\title{
Desempenho agronômico e supressão de plantas daninhas no sorgo em semeadura adensada
}

\author{
Agronomic performance and weed suppression in sorghum on dense sowing \\ Guilherme Braga Pereira Braz', Fellipe Goulart Machado², Eduardo Lima do Carmo', Antonio \\ Germano Carpim Rocha ${ }^{1}$, Gustavo André Simon ${ }^{1}$ e Camila Jorge Bernabé Ferreira ${ }^{1 *}$ \\ 1Universidade de Rio Verde, Rio Verde, GO, Brasil. *Autor para correspondência: camilajbferreira@gmail.com. \\ ${ }^{2}$ Universidade Estadual de Maringá, Maringá, PR, Brasil.
}

Submissão: 24/08/2018 / Aceite: 25/02/2019

\begin{abstract}
RESUMO
A semeadura do sorgo adensado pode influenciar no manejo cultural de plantas daninhas e desempenho produtivo da cultura. Sendo assim, o objetivo deste trabalho foi avaliar a influência do adensamento na semeadura do sorgo sobre o desenvolvimento agronômico da cultura e supressão de plantas daninhas. $O$ experimento foi conduzido a campo no delineamento blocos casualizados. Os tratamentos foram dispostos em arranjo fatorial $2 \times 2 \times 2$, adotando oito repetições. $O$ primeiro fator consistiu em dois espaçamentos entre linhas, 0,50 e $0,25 \mathrm{~m}$; o segundo fator foi composto por duas populações, $180.000 \mathrm{e}$ 270.000 plantas ha $^{-1}$; por fim, o terceiro fator correspondeu à convivência ou não com a comunidade infestante. Para o sorgo, foi avaliada a altura de plantas, comprimento e massa de panícula, massa de mil grãos e produtividade. Para as plantas daninhas, avaliou-se densidade e massa seca. $O$ espaçamento entre linhas e a população de plantas influenciou os componentes de rendimento do sorgo, sem, contudo, apresentar efeito sobre a produtividade. A interferência das plantas daninhas durante todo o ciclo de desenvolvimento do sorgo promoveu redução na produtividade. $O$ adensamento de plantas no cultivo do sorgo proporcionou redução da densidade de infestação e massa seca de plantas daninhas.
\end{abstract}

PALAVRAS-CHAVE: comunidade infestante, métodos alternativos de manejo, Sorghum bicolor.

\begin{abstract}
The dense sowing of sorghum can influence the crop yield performance. In addition, this practice can also be used in the cultural management of weeds. This study aimed to evaluate the influence of densification on sorghum sowing, agronomic crop development, and weed suppression. The experiment was conducted in the field in the randomized complete block design. The treatments were arranged in factorial arrangement $2 \times 2 \times 2$, adopting eight replications. The first factor consisted of two row spacings, 0,50 and $0,25 \mathrm{~m}$; the second factor was composed of two populations, 180,000 and 270,000 plants ha- 1 ; finally, the third factor corresponded to the cohabitation or not with the weeds. For sorghum, the height of plants, length and panicle mass, mass of one thousand grains, and yield were evaluated. Weeds were evaluated for density and dry mass. Row spacing and plant population influenced sorghum yield components, but they did not have effect on the yield. Weed interference during the entire development cycle of sorghum reduced its yield. The densification of plants in sorghum cultivation reduced weed density and weed dry mass.
\end{abstract}

KEYWORDS: weed community, alternative management methods, Sorghum bicolor.

\section{INTRODUÇÃO}

O sorgo granífero [Sorghum bicolor (L.) Moench.] pertence à família Poaceae, possui metabolismo fotossintético $\mathrm{C}_{4}$ e caracteriza-se por ser espécie típica de cultivo de segunda safra, devido ao fato de apresentar maior tolerância a estresses hídricos quando comparado ao milho, consistindo em alternativa para semeaduras mais tardias no Cerrado brasileiro (MAGALHÃES et al. 2014). Na safra 2016/2017, a produção brasileira foi de 1888,4 mil toneladas em 653,8 mil hectares cultivados, com produtividade média de $2967 \mathrm{~kg} \mathrm{ha}^{-1}$. Os estados de Goiás e Minas Gerais foram os principais produtores nacionais, com produtividade média de $3500 \mathrm{~kg} \mathrm{ha}^{-1}$ (CONAB 2018). 
Para almejar maiores produtividades, fatores que podem reduzir o potencial produtivo do sorgo, como ataque de pragas, doenças e a interferência das plantas daninhas, devem ser manejados de forma adequada. Dentre estes fatores que causam prejuízos para o desenvolvimento da cultura, destaca-se a problemática relacionada à convivência com a comunidade infestante. As plantas daninhas podem interferir no desenvolvimento do sorgo por meio da competição por água, nutrientes, luz e espaço físico (VASCONCELOS et al. 2012). Além dos efeitos diretos provocados pelas plantas daninhas, estas ocasionam perdas quando em convivência com a cultura pelo fato de apresentarem potencial de hospedar pragas e doenças (SILVA et al. 2007, CABRAL et al. 2013).

A escassez de herbicidas registrados para o controle de espécies gramíneas, aliada ao crescimento inicial lento do sorgo, podem aumentar a interferência das plantas daninhas com a cultura (RIZZARDI et al. 2004). Atualmente, os herbicidas registrados para o sorgo são glyphosate e paraquat, os quais são posicionados para uso na dessecação pré-semeadura, e atrazine e 2,4-D amina para aplicações em pósemergência da cultura (MAPA 2018).

Dados apresentados na literatura demonstram potencial de redução na produtividade do sorgo pela convivência com as plantas daninhas em valores variando entre 20 e $80 \%$. A intensidade será dependente da densidade de infestação, período de convivência e diversidade da composição florística da comunidade infestante (RODRIGUES et al. 2010, CABRAL et al. 2013). Além disso, já foi determinado que o período crítico de prevenção da interferência, o qual se relaciona com o momento em que a cultura deve se manter livre da convivência com a comunidade infestante, foi dos 23 aos 42 dias após a emergência do sorgo, sendo necessária a adoção de medidas de controle das plantas daninhas (CABRAL et al. 2013).

Uma das formas de manejo das plantas daninhas sem utilização de herbicidas é o controle cultural, que visa criar um ambiente mais favorável para a cultura frente às plantas daninhas. Dentre as técnicas de manejo cultural do sorgo, destacam-se a utilização de cultivares de crescimento rápido, redução do espaçamento entre linhas e aumento da densidade de plantas (PEERZADA et al. 2016). Técnicas de controle cultural como redução do espaçamento das entrelinhas e o aumento da densidade de plantas restringem a emergência e o desenvolvimento das plantas daninhas devido ao aumento do poder competitivo da cultura (OLSEN et al. 2012).

A utilização de semeaduras adensadas promove maior interceptação de luz pela cultura, consistindo em uma das principais práticas relacionadas ao método de manejo cultural da comunidade infestante (PEERZADA et al. 2016). Plantas com maior desenvolvimento inicial promovem o fechamento das entrelinhas mais rápido e, consequentemente, reduzem a incidência de luz no solo, proporcionando um ambiente desfavorável à germinação e emergência das plantas daninhas (RODRIGUES et al. 2010).

Apesar dos benefícios da redução de espaçamento e aumento da densidade de semeadura para o manejo das plantas daninhas no sorgo, o desempenho agronômico da cultura pode variar em função destas características, sendo necessário avaliar os efeitos destas práticas sobre a produtividade (ALBUQUERQUE et al. 2011). Deste modo, a avalição das características agronômicas do sorgo granífero e da infestação das plantas daninhas em função do aumento da densidade de semeadura e redução do espaçamento das entrelinhas é essencial para formular novas estratégias de controle cultural da comunidade infestante.

A partir deste contexto, este trabalho teve como objetivo avaliar a influência do adensamento na semeadura do sorgo sobre o desenvolvimento agronômico da cultura e a infestação de plantas daninhas.

\section{MATERIAL E MÉTODOS}

O experimento foi conduzido na área experimental da Universidade de Rio Verde (UniRV), localizada no munícipio de Rio Verde, GO, nas coordenadas geográficas $17^{\circ} 48^{\prime}$ de latitude sul e $50^{\circ} 55^{\prime}$ de longitude oeste, em uma altitude de $770 \mathrm{~m}$, apresentando relevo plano (declividade média menor que $3 \%$ ). O período de condução do experimento foi entre fevereiro e junho de 2017.

Segundo a classificação de Köppen, o clima para a localidade em que o experimento foi conduzido é do tipo Aw, identificado como clima tropical com estação seca, caracterizado por apresentar chuvas mais intensas no verão em comparação ao inverno. A média anual da precipitação é de $1.500 \mathrm{~mm}$ e a média anual da temperatura é de $23 \stackrel{\circ}{\circ}$. Os dados de precipitação e temperatura máxima e mínima do ar durante a condução do experimento estão apresentados na Figura 1.

O solo da área experimental foi classificado como Latossolo Vermelho distrófico (EMBRAPA 2013), explorado em sistema de plantio direto há mais de 15 anos e a cultura antecessora foi a soja. Anteriormente à instalação do experimento, foi realizada a amostragem de solo na profundidade de $0-0,20 \mathrm{~m}$ para a caracterização química e física. Nesta ocasião, o solo da área experimental apresentava $\mathrm{pH}$ em $\mathrm{CaCl}_{2}$ de 5,2; $4,5 \mathrm{cmol}_{\mathrm{c}}$ de $\mathrm{H}^{+}+\mathrm{Al}^{+3} \mathrm{dm}^{-3} ; 2,0 \mathrm{cmol}_{\mathrm{c}} \mathrm{dm}^{-3} \mathrm{de} \mathrm{Ca}^{+2} ; 1,09 \mathrm{cmol}_{\mathrm{c}} \mathrm{dm}^{-3} \mathrm{de} \mathrm{Mg}^{+2} ; 0,36 \mathrm{cmol}_{\mathrm{c}} \mathrm{dm}^{-3} \mathrm{de} \mathrm{K}^{+} ; 1,89$ 
$\mathrm{mg} \mathrm{dm}^{-3}$ de P; $23,70 \mathrm{~g} \mathrm{~kg}^{-1}$ de M.O.; $580 \mathrm{~g} \mathrm{~kg}^{-1}$ de argila, $80 \mathrm{~g} \mathrm{~kg}^{-1}$ de silte, $340 \mathrm{~g} \mathrm{~kg}^{-1}$ de areia, pertencente à classe textural argilosa.

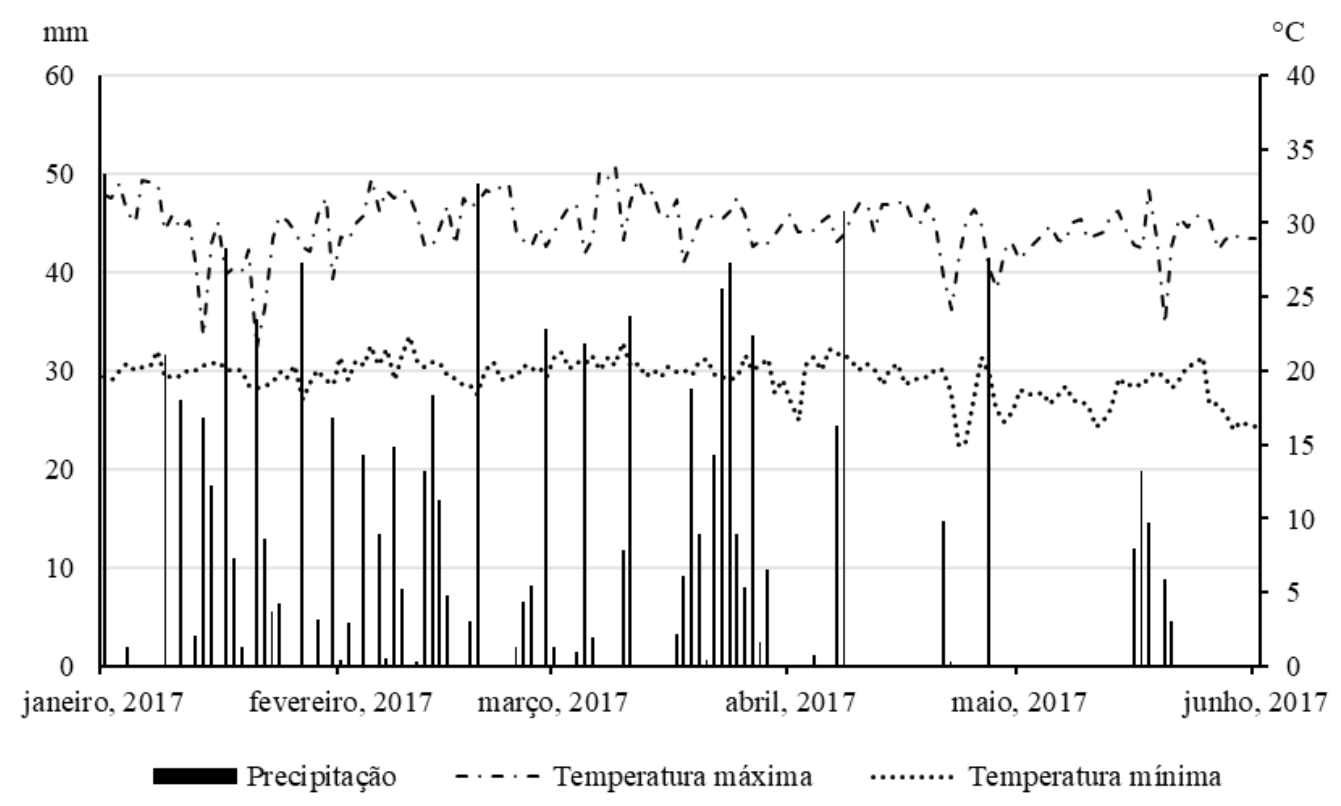

Figura 1. Dados meteorológicos (temperaturas máxima e mínima e precipitação pluviométrica) coletados durante o período de condução do experimento com a cultura do sorgo.

Figure 1. Meteorological data (maximum and minimum temperature and rainfall) collected during the conduction of the experiment with sorghum crop.

O delineamento utilizado foi de blocos casualizados sendo os tratamentos dispostos em arranjo fatorial triplo $2 \times 2 \times 2$, com oito repetições. O primeiro fator consistiu em dois espaçamentos entre linhas de semeadura, 0,50 e $0,25 \mathrm{~m}$; o segundo fator foi composto por duas populações, 180.000 plantas ha-1 $^{-1}$ (recomendada) e 270.000 plantas ha-1 (adensada); por fim, o terceiro fator correspondeu à convivência ou não com a comunidade infestante (capinado e no mato). Nas parcelas em que foram alocados os tratamentos sem a interferência de plantas daninhas (capinado), essas foram removidas por meio de capinas manuais.

Parcelas semeadas com espaçamento entre linhas de $0,50 \mathrm{~m}$ foram compostas por quatro linhas de semeadura de sorgo e as parcelas com espaçamento entre linhas de $0,25 \mathrm{~m}$ foram constituídas por sete linhas de semeadura de sorgo, ambas com comprimento de $6 \mathrm{~m}$, com área útil equivalente à $4 \mathrm{~m}^{2}$. $\mathrm{A}$ semeadura do sorgo foi realizada no dia 18/02/2017, com a cultivar 1G100 ${ }^{\circledR}$ (DOW AGROSCIENCES 2016), adotando-se densidade de semeadura que possibilitasse a obtenção de população final de 300.000 plantas por hectare. Aos sete dias após a emergência da cultura, foi realizado o desbaste das plantas, permanecendo nas unidades experimentais a população prevista em cada tratamento a ser avaliado.

$\mathrm{Na}$ ocasião de implantação da cultura, foi realizada adubação no sulco de semeadura utilizando MAP na dose de $150 \mathrm{~kg} \mathrm{ha}{ }^{-1}$. Ao longo do ciclo da cultura, foi realizada uma adubação em cobertura (09/03/2017), utilizando como fonte ureia na dose de $180 \mathrm{~kg} \mathrm{ha}^{-1}$ e cloreto de potássio na dose de $180 \mathrm{~kg}$ ha $^{-1}$. Os tratos culturais foram realizados de acordo com as recomendações técnicas para condução de lavouras comerciais de sorgo, visando assegurar o potencial produtivo máximo da cultura. Além disso, após a fecundação das panículas das plantas de sorgo, estas foram cobertas com sacos de papel kraft para evitar perdas na produção devido ao ataque de pássaros.

As variáveis-respostas avaliadas em relação ao efeito dos tratamentos na cultura do sorgo foram altura inicial e final de plantas, comprimento e massa de panícula, massa de mil grãos e produtividade de grãos. Excluindo a variável altura inicial de plantas, a qual foi realizada aos 40 dias após a emergência da cultura, correspondente ao estádio fenológico 4, o qual se caracteriza pela folha bandeira estar visível, todas as demais avaliações foram realizadas na ocasião da colheita do sorgo. Para as avaliações de altura inicial e final, foi realizada a medição da altura da planta desde o nível do solo até a inserção da última folha completamente expandida e até o ápice da panícula, respectivamente, sendo realizadas sete amostras por unidade experimental.

Com relação ao comprimento de panícula, foram selecionadas aleatoriamente sete plantas de sorgo 
por unidade experimental, as quais tiveram o comprimento da panícula medido da base do ráquis até o ápice da panícula. A massa de panícula foi mensurada por meio da pesagem de sete panículas de planta de sorgo por unidade experimental. A massa de mil grãos foi obtida pela contagem de mil grãos oriundos das plantas presentes na área útil de cada unidade experimental que recebeu os tratamentos, e posteriormente estes foram pesados em balança de precisão e tiveram a umidade corrigida para $13 \%$.

Em relação à produtividade, as panículas das plantas de sorgo presentes na área útil foram coletadas no dia 28/06/2017 e posteriormente trilhadas e tiveram a umidade corrigida para $13 \%$. O valor de produção obtido por unidade experimental foi convertido para hectare, apresentando os resultados de produtividade em kg ha-1.

Além das variáveis relacionadas à cultura, na ocasião da colheita foram realizadas avaliações de densidade e massa seca de plantas daninhas. Para a avaliação da densidade de infestação das plantas daninhas, foi lançado um quadrado metálico de $0,25 \mathrm{~m}^{2}$ duas vezes de forma aleatória nas unidades experimentais, e posteriormente se procedeu à contagem de plantas daninhas presentes na área amostrada.

Em relação à massa seca de plantas daninhas, foi coletada a parte aérea das espécies presentes no mesmo quadrado metálico utilizado na avaliação de densidade de infestação. Após a coleta do material vegetal, ele foi acondicionado em sacos de papel kraft e colocado em estufa de circulação forçada de ar à temperatura de $65 \stackrel{\circ}{\circ}$ pelo período de 72 horas, e após atingirem massa constante, o material foi pesado em balança de precisão. Para as variáveis relacionadas à comunidade infestante, os resultados foram expressos com a conversão dos valores para área equivalente a $1 \mathrm{~m}^{2}$.

A análise estatística foi realizada utilizando-se o software SISVAR (FERREIRA 2011). Os dados das avaliações relacionadas à cultura do sorgo foram submetidos à análise de variância e quando constatado efeito significativo, foi empregado o teste $F(p \leq 0,10)$ para comparar os tratamentos.

Para as variáveis-respostas relacionadas às plantas daninhas, a análise estatística foi realizada desconsiderando-se o terceiro fator (convivência com a comunidade infestante), procedendo-se à análise como se o experimento fora conduzido em arranjo fatorial $2 \times 2$, utilizando-se os dados provenientes dos tratamentos com a presença de plantas daninhas, sendo empregado o mesmo método estatístico que 0 utilizado para as avaliações do sorgo.

\section{RESULTADOS E DISCUSSÃO}

$\mathrm{Na}$ Tabela 1, está apresentado o resumo da análise da variância para as variáveis-respostas relacionadas ao sorgo. Não foi observado efeito da interação entre os fatores para as variáveis estudadas, sendo constatado efeito significativo apenas aos fatores isolados. A não ocorrência do efeito da interação entre os fatores demonstra que os diferentes espaçamentos, populações de plantas ou convivência com as plantas daninhas não influenciaram de maneira integrada as variáveis analisadas na cultura do sorgo no presente estudo.

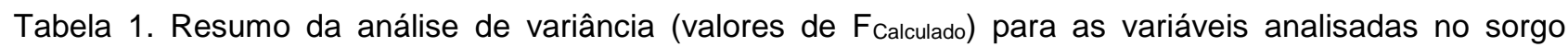
cultivado em diferentes arranjos de plantas e manejo da comunidade infestante.

Table1. Summary of variance analysis ( $F$ values) for the variables analyzed in sorghum cultivated on different plant arrangements and weed community management.

\begin{tabular}{llllllll}
\hline FV & GL & API & APF & CP & MP & MMG & PROD \\
\hline Espaçamento (ESP) & 1 & $13,18^{*}$ & $9,07^{*}$ & $4,71^{*}$ & $11,44^{*}$ & $35,19^{*}$ & $1,58^{\text {ns }}$ \\
População (POP) & 1 & $0,96^{\text {ns }}$ & $3,29^{*}$ & $6,64^{*}$ & $31,13^{*}$ & $3,12^{*}$ & $0,02^{\text {ns }}$ \\
Planta daninha (PD) & 1 & $0,87^{\text {ns }}$ & $0,01^{\text {ns }}$ & $1,07^{\text {ns }}$ & $0,34^{\text {ns }}$ & $0,07^{\text {ns }}$ & $2,94^{*}$ \\
ESP x POP & 1 & $0,33^{\text {ns }}$ & $0,11^{\text {ns }}$ & $1,60^{\text {ns }}$ & $0,43^{\text {ns }}$ & $0,56^{\text {ns }}$ & $1,50^{\text {ns }}$ \\
ESP x PD & 1 & $0,13^{\text {ns }}$ & $0,10^{\text {ns }}$ & $0,17^{\text {ns }}$ & $0,43^{\text {ns }}$ & $0,98^{\text {ns }}$ & $0,04^{\text {ns }}$ \\
POP x PD & 1 & $0,80^{\text {ns }}$ & $0,09^{\text {ns }}$ & $0,22^{\text {ns }}$ & $0,38^{\text {ns }}$ & $1,17^{\text {ns }}$ & $0,03^{\text {ns }}$ \\
ESP x POP x PD & 1 & $0,02^{\text {ns }}$ & $0,05^{\text {ns }}$ & $0,01^{\text {ns }}$ & $1,40^{\text {ns }}$ & $0,20^{\text {ns }}$ & $0,22^{\text {ns }}$ \\
Bloco & 7 & 0,22 & 0,77 & 0,37 & 5,48 & 2,54 & 3,23 \\
\hline Resíduo & 49 & - & - & - & - & - & - \\
\hline CV $(\%)$ & - & 9,10 & 4,41 & 8,33 & 14,00 & 4,81 & 17,31
\end{tabular}

$\overline{\mathrm{API}}=$ Altura de plantas inicial; $\mathrm{APF}=$ Altura de plantas final; $\mathrm{CP}=$ Comprimento de panícula; $\mathrm{MP}=$ Massa de panícula; $M M G=$ Massa de mil grãos; $P R O D=$ Produtividade de grãos. ${ }^{*}=$ Significativo a $10 \%$ de probabilidade pelo teste $F ;$ ${ }^{\mathrm{ns}}=$ não significativo. 
Ainda com relação aos resultados apresentados na Tabela 1, verificou-se que a utilização de espaçamentos distintos na semeadura do sorgo teve efeito significativo sobre a altura de plantas (inicial e final), comprimento e massa de panícula, além da massa de mil grãos. Com exceção da altura inicial, houve semelhante efeito da população de plantas sobre as mesmas características que os espaçamentos entre linhas influenciaram. Por fim, a convivência ou não com as plantas daninhas apresentou efeito significativo apenas sobre a produtividade de grãos da cultura do sorgo.

As plantas de sorgo que se desenvolveram nas unidades experimentais em que foi utilizado o espaçamento entre linhas de $0,50 \mathrm{~m}$ na semeadura apresentaram valores de altura inicial superiores em relação àquelas que foram cultivadas no espaçamento de $0,25 \mathrm{~m}$, comportamento que também foi observado na avaliação de altura realizada na ocasião da colheita da cultura (Tabela 2).

Tabela 2. Variáveis relacionadas ao sorgo em função da adoção de diferentes espaçamentos entre linhas e populações na semeadura da cultura.

Table 2. Variables related to sorghum due to the adoption of different spacing between rows and populations in the crop sowing.

\begin{tabular}{|c|c|c|c|c|c|c|c|c|c|c|}
\hline \multirow{2}{*}{$\begin{array}{l}\text { Espaçamento } \\
0,25 \mathrm{~m}\end{array}$} & \multicolumn{2}{|c|}{ API $(\mathrm{cm})$} & \multicolumn{2}{|c|}{ APF $(\mathrm{cm})$} & \multicolumn{2}{|c|}{$\mathrm{CP}(\mathrm{cm})$} & \multicolumn{2}{|c|}{ MP (g) } & \multicolumn{2}{|c|}{ MMG (g) } \\
\hline & 37,42 & $b^{(1)}$ & 111,78 & $\mathrm{~b}$ & 26,70 & $\mathrm{~b}$ & 47,43 & $\mathrm{~b}$ & 19,80 & $\mathrm{~b}$ \\
\hline $0,50 \mathrm{~m}$ & 40,65 & $\mathrm{a}$ & 115,55 & $\mathrm{a}$ & 27,93 & $\mathrm{a}$ & 53,40 & $\mathrm{a}$ & 21,25 & $\mathrm{a}$ \\
\hline \multicolumn{11}{|l|}{ População } \\
\hline Recomendada & 38,60 & a & 112,53 & b & 28,05 & a & 55,34 & $a$ & 20,75 & $\mathrm{a}$ \\
\hline Adensada & 39,47 & a & 114,80 & a & 26,58 & b & 45,50 & $b$ & 20,30 & $\mathrm{~b}$ \\
\hline
\end{tabular}

$\overline{\mathrm{API}}=$ Altura de plantas inicial; $\mathrm{APF}=$ Altura de plantas final; $\mathrm{CP}=$ Comprimento de panícula; $\mathrm{MP}=$ Massa de panícula; $M M G=$ Massa de mil grãos. ${ }^{(1)}$ Médias seguidas por letras distintas na coluna diferem entre si pelo teste $F$ a $10 \%$ de probabilidade.

Quando se utiliza uma mesma população de plantas por hectare e se procede à redução no espaçamento entre linhas de semeadura, o que acaba por ocorrer é uma diminuição do número de plantas por metro linear em relação ao espaçamento mais largo na entrelinha. A utilização de maiores densidades de plantas por metro linear contribui para que aconteça a competição intraespecífica, especialmente por luz e nutrientes (KAPPES et al. 2011). Os resultados das avaliações de altura indicam possiblidade de ter havido competição por luz, visto que as plantas submetidas ao maior adensamento na linha de semeadura (espaçamento entre linhas de $0,50 \mathrm{~m}$ ) apresentaram maior porte, comportamento que pode ser oriundo do estiolamento. $O$ aumento da altura das plantas em virtude da competição por luz expressa o resultado da alteração de processos fisiológicos relacionados à dinâmica hormonal das plantas, bem como dos processos de divisão celular (MEROTTO JR. et al. 2002).

Tanto o comprimento como a massa de panícula foram maiores nas plantas de sorgo que foram cultivadas no espaçamento mais largo $(0,50 \mathrm{~m})$ (Tabela 2). Para estas variáveis-respostas (comprimento e massa seca de panícula), houve incremento da ordem de 4,6 e 12,6\%, respectivamente, quando o sorgo foi semeado a 0,50 m entre linhas de distância em relação ao espaçamento adensado $(0,25 \mathrm{~m})$.

Apesar de ambas as variáveis supracitadas não consistirem em componentes de rendimento do sorgo, elas possuem relação com a produtividade da cultura. Em geral, panículas maiores e mais pesadas tendem a apresentar maior número de grãos e/ou grãos com maior massa, fato que se correlaciona à obtenção de rendimentos mais elevados (TOLK et al. 2013). Além disso, com o intuito de ter uma estimativa mais próxima da produtividade do sorgo, sempre é interessante a avaliação dos componentes de rendimento reais da cultura, sendo estes o número de panículas por hectare e de grãos por panícula e a massa de mil grãos (SILVA et al. 2015).

Semelhantemente ao observado para as demais variáveis influenciadas pelos espaçamentos entre linhas, para a massa de mil grãos, novamente foram observados valores mais elevados nas plantas provenientes das parcelas semeadas no espaçamento $0,50 \mathrm{~m}$, quando comparadas ao 0,25 $\mathrm{m}$ (Tabela 2). Apesar disso, quando se compara a produtividade dos dois espaçamentos, verifica-se que não há influência deste fator (Tabela 1). Possivelmente, as plantas de sorgo semeadas no espaçamento 0,25 m, apesar de possuírem menor massa de grãos, apresentaram a capacidade de compensar a redução desta variável por meio do aumento de outro componente de rendimento que não foi avaliado no presente trabalho.

$\mathrm{Na}$ literatura, existem trabalhos que demonstram que há incremento na produtividade do sorgo ao se proceder à redução do espaçamento entre linhas na semeadura da cultura (ALBUQUERQUE et al. 2010, 
ALBUQUERQUE et al. 2011). O fato de o presente trabalho não ter corroborado à resultados obtidos em outros estudos, quanto ao efeito da redução do espaçamento sobre a produtividade, podem estar relacionados a características específicas da cultivar que foi utilizada no experimento, uma vez que cada material responde de maneira distinta às práticas de manejo a que é exposto.

Em relação ao efeito da população sobre as variáveis analisadas (Tabela 2), verifica-se que a semeadura mais adensada do sorgo proporcionou a obtenção de plantas com estatura mais elevada na ocasião da colheita, quando comparado com o tratamento em que foi utilizada a população recomendada pela empresa detentora da cultivar. Este comportamento corrobora 0 verificado para 0 efeito que 0 espaçamento entre linhas apresentou sobre esta variável-resposta, uma vez que à medida que se aumentou o número de plantas por metro linear, também houve aumento na altura do sorgo.

Para as variáveis relacionadas à panícula das plantas de sorgo, nota-se que nos tratamentos semeados com a população recomendada (180.000 plantas ha-1), tanto o comprimento como a massa de panícula se apresentavam com maiores valores em comparação com os tratamentos em que se procedeu à semeadura adensada. Apesar do incremento ter sido verificado para ambas as variáveis, este apresentouse mais notório para a massa de panícula, tendo em vista que, para esta, o aumento observado foi equivalente a $21,6 \%$, enquanto que para o comprimento de panícula o valor ficou próximo de $5,5 \%$. Em trabalho realizado por CRUSCIOL et al. (2011), também foi verificada a tendência de se observar plantas com panículas de maior tamanho à medida que a semeadura foi realizada com densidades populacionais menores.

A massa de mil grãos de sorgo foi superior nos tratamentos em que a semeadura da cultura foi realizada na população recomendada (Tabela 2). Apesar de numericamente a superioridade para massa de mil grãos da população recomendada em relação à adensada parecer pequena, por esta variável consistir em componente do rendimento do sorgo, este aumento se torna importante do ponto de vista de recomendação técnica para 0 manejo, pois ela afeta de maneira direta a produtividade da cultura (CRUSCIOL et al. 2011).

Conforme mencionado anteriormente, o único fator a influenciar de maneira direta a produtividade do sorgo foi a convivência das plantas daninhas com a cultura durante o seu ciclo. As parcelas que foram mantidas livres da interferência da comunidade infestante apresentaram produtividade de grãos de aproximadamente $370 \mathrm{~kg} \mathrm{ha}^{-1}$ a mais em relação àquelas em que houve a presença de plantas daninhas ao longo do desenvolvimento do sorgo (Tabela 3). Em valores percentuais, esta queda corresponde a uma redução de $7,2 \%$ da produtividade da cultura.

Tabela 3. Produtividade de grãos do sorgo em função da presença de plantas daninhas em convivência com a cultura.

Table 3. Sorghum grain yield as a function of the presence of weeds in coexistence with the crop.

\begin{tabular}{lll}
\hline Espaçamento & Produtividade $\left(\mathrm{kg} \mathrm{ha}^{-1}\right)$ & \\
\hline $0,25 \mathrm{~m}$ & 4843,13 & $\mathrm{a}^{(1)}$ \\
$0,50 \mathrm{~m}$ & 5114,53 & $\mathrm{a}$ \\
\hline População & & \\
\hline Recomendada & 4961,08 & $\mathrm{a}$ \\
Adensada & 4996,63 & $\mathrm{a}$ \\
\hline Planta daninha & & \\
\hline Capinado & 5163,73 & $\mathrm{a}$ \\
Mato & 4793,97 & $\mathrm{~b}$ \\
\hline
\end{tabular}

(1)Médias seguidas por letras distintas na coluna diferem entre si pelo teste $\mathrm{F}$ a $10 \%$ de probabilidade.

Apesar de ter sido verificado o efeito negativo das plantas daninhas sobre a produtividade da cultura do sorgo, as reduções observadas no presente experimento foram inferiores às relatadas em outros trabalhos apresentados na literatura (RODRIGUES et al. 2010, CABRAL et al. 2013). Uma possível explicação para este fato pode estar relacionada às condições ótimas a que a cultura foi submetida ao longo do seu ciclo, uma vez que não foi exposta a déficit hídrico (Figura 1), além de as práticas de manejo (adubação) terem sido realizadas visando à obtenção de altas produtividades. Neste contexto, o processo de competição pode ter sido atenuado por não haver grandes limitações de recursos, tais como água e nutrientes, os quais são necessários para o desenvolvimento da cultura e da comunidade infestante.

A interação entre os fatores espaçamento entre linhas e população de plantas utilizados na 
semeadura do sorgo não apresentou efeito significativo sobre as variáveis-respostas relacionadas à comunidade infestante (Tabela 4). A utilização das diferentes populações na implantação da cultura apresentou influência na densidade de infestação e massa seca de plantas daninhas, enquanto que o fator espaçamento entre linhas teve efeito significativo apenas sobre a massa seca de plantas daninhas.

Tabela 4. Resumo da análise de variância (valores de $\mathrm{F}_{\text {Calculado) }}$ para as variáveis relacionadas às plantas daninhas que se desenvolveram no sorgo cultivado em diferentes arranjos de plantas.

Table 4. Summary of variance analysis ( $F$ values) for variables related to weeds that developed in sorghum grown on different plant arrangements.

\begin{tabular}{llll}
\hline FV & GL & DPD & MSPD \\
\hline Espaçamento (ESP) & 1 & $0,95^{\text {ns }}$ & $3,19^{*}$ \\
População (POP) & 1 & $3,98^{*}$ & $4,51^{*}$ \\
ESP x POP & 1 & $0,04^{\text {ns }}$ & $1,20^{\text {ns }}$ \\
Bloco & 7 & 2,76 & 1,89 \\
\hline Resíduo & 21 & - & - \\
\hline CV (\%) & - & 48,03 & 74,87 \\
\hline
\end{tabular}
probabilidade pelo teste $\mathrm{F} ;{ }^{\text {ns }}=$ não significativo.

A massa seca das plantas daninhas foi menor quando a cultura do sorgo foi semeada no espaçamento entre linhas de $0,25 \mathrm{~m}$ (Tabela 5). Este resultado, juntamente com o da avaliação de densidade de infestação, demonstra que a diminuição nas entrelinhas de semeadura do sorgo, apesar de não reduzir o número de indivíduos que compõem a flora infestante da cultura, proporciona restrição no desenvolvimento das plantas daninhas.

Tabela 5. Variáveis relacionadas às plantas daninhas em função do arranjo espacial utilizado na semeadura do sorgo.

Table 5. Variables related to weeds as a function of the spatial arrangement used in sorghum sowing.

\begin{tabular}{llclc}
\hline Espaçamento & \multicolumn{2}{c}{ Densidade de infestação $\left(\right.$ número $\left.\mathrm{m}^{-2}\right)$} & \multicolumn{2}{l}{ Massa seca de plantas daninhas $\left(\mathrm{g} \mathrm{m}^{-2}\right)$} \\
\hline $0,25 \mathrm{~m}$ & 84,64 & $\mathrm{a}^{(1)}$ & 473,44 & $\mathrm{~b}$ \\
$0,50 \mathrm{~m}$ & 100,00 & $\mathrm{a}$ & 766,88 & $\mathrm{a}$ \\
\hline População & & & \\
\hline Recomendada & 108,00 & $\mathrm{a}$ & 794,56 & $\mathrm{a}$ \\
Adensada & 76,64 & $\mathrm{~b}$ & 445,76 & $\mathrm{~b}$ \\
\hline
\end{tabular}

(1) Médias seguidas por letras distintas na coluna diferem entre si pelo teste $\mathrm{F}$ a $10 \%$ de probabilidade.

A diminuição da massa de plantas daninhas traz uma série de benefícios para o desenvolvimento do sorgo, destacando-se entre os principais a menor capacidade competitiva da comunidade infestante com a cultura, devido às plantas infestantes se apresentarem menos vigorosas (CARVALHO et al. 2011), e a facilidade na execução do controle químico por meio da aplicação de herbicidas em pós-emergência (MEROTTO JR. et al. 2001).

O aumento da população na semeadura do sorgo promoveu redução na densidade e na massa seca das plantas daninhas (Tabela 5). As reduções observadas na densidade de infestação e massa seca de plantas daninhas foram de, aproximadamente, 29 e 44\%, quando se realizou a semeadura adensada do sorgo, o que demonstra que esta prática cultural, apesar de não proporcionar aumento na produtividade, traz como benefício a diminuição do poder de interferência da comunidade infestante com a cultura.

$\mathrm{O}$ aumento da densidade de plantas reduziu o crescimento das plantas daninhas. Possivelmente, o adensamento das plantas aumentou a interceptação solar pela cultura, o que reduz a quantidade de luz que chega ao solo, e consequentemente interfere nos processos de germinação e crescimento das plantas daninhas (OLSEN et al. 2012). A integração do controle químico com controle cultural para o manejo das plantas daninhas se torna fundamental para manutenção do sistema produtivo, principalmente quando há infestantes de difícil controle com resistência a herbicidas (PEERZADA et al. 2016). 


\section{CONCLUSÃO}

A semeadura em espaçamento entre linhas de $0,25 \mathrm{~m}$ causa redução no tamanho da panícula e na massa de mil grãos das plantas de sorgo em relação ao espaçamento de $0,50 \mathrm{~m}$. O aumento da população na semeadura do sorgo (270.000 plantas ha-1) proporciona diminuição do tamanho da panícula e da massa de mil grãos das plantas quando comparado com o cultivo realizado na população recomendada (180.000 plantas ha-1).

Apesar do espaçamento entre linhas e população de plantas terem influenciado o desenvolvimento da cultura, estes não apresentaram efeito sobre a produtividade de grãos do sorgo. A convivência com as plantas daninhas durante todo o ciclo de desenvolvimento do sorgo promove redução na produtividade.

$\mathrm{O}$ adensamento das entrelinhas de semeadura do sorgo ou da população de plantas proporciona diminuição da massa seca de plantas daninhas.

\section{REFERÊNCIAS}

ALBUQUERQUE CJB et al. 2010. Reduced spacing for Sorghum bicolor in the irrigated and rainfed systems. Pesquisa Aplicada \& Agrotecnologia 3: 7-16.

ALBUQUERQUE CJB et al. 2011. Espaçamento e densidade de semeadura para cultivares de sorgo granífero no semiárido. Bragantia 70: 278-285.

CABRAL PHR et al. 2013. Interferência de plantas daninhas na cultura do sorgo cultivado em safrinha. Pesquisa Agropecuária Tropical 43: 308-314.

CARVALHO FP et al. 2011. Alocação de matéria seca e capacidade competitiva de cultivares de milho com plantas daninhas. Planta Daninha 29: 373-382.

CONAB. 2018. Companhia Nacional de Abastecimento. Acompanhamento da safra brasileira: grãos 2017/2018. Disponível em: http://www.conab.gov.br/OlalaCMS/uploads/arquivos/18_02_08_17_09_36_fevereiro_2018.pdf. Acesso em: 16 fev. 2018.

CRUSCIOL CAC et al. 2011. Nutrição e produtividade de híbridos de sorgo granífero de ciclos contrastantes consorciados com capim-marandu. Pesquisa Agropecuária Brasileira 46: 1234-1240.

DOW AGROSCIENCES. 2016. Catálogo de híbridos de sorgo 2016. Disponível em: http://msdssearch.dow.com/PublishedLiteratureDAS/dh_0965/0901b803809652fb.pdf?filepath=br/pdfs/noreg/013-051 77.pdf\&fromPage =GetDoc/. Acesso em: 12 fev. 2018.

EMBRAPA. 2013. Empresa Brasileira de Pesquisa Agropecuária. Sistema Brasileiro de Classificação de Solos. 3.ed. Brasília: EMBRAPA Solos. 353p.

FERREIRA DF 2011. Sisvar: a computer statistical analysis system. Ciência e Agrotecnologia 35: 1039-1042.

KAPPES $C$ et al. 2011. Desempenho de híbridos de milho em diferentes arranjos espaciais de plantas. Bragantia 70 : 334-343.

MAGALHÃES PC et al. 2014. Exigências edafoclimáticas e fisiologia da produção. In: BORÉM A (Ed.). Sorgo: do plantio à colheita. Viçosa: UFV. p.58-88.

MAPA. 2018. Ministério da Agricultura, Pecuária e Abastecimento. Sistema de Agrotóxicos Fitossanitários/Agrofit. Disponível em: <http://www.agricultura.gov.br/servicos-e-sistemas/sistemas/agrofitl>. Acesso em: 17 out. 2018.

MEROTTO JR. A et al. 2002. Interferência das plantas daninhas sobre o desenvolvimento inicial de plantas de soja e arroz através da qualidade da luz. Planta Daninha 20: 9-16.

MEROTTO JR. A et al. 2001. Variação da competição interespecífica em milho em função do controle de plantas daninhas em faixas. Planta Daninha 19: 287-294.

OLSEN JM et al. 2012. How important are crop spatial pattern and density for weed suppression by spring wheat? Weed Science 60: 501-509.

PEERZADA AM et al. 2016. Weed management in sorghum [Sorghum bicolor (L.) Moench] using crop competition: a review. Crop Protection 95: 74-80.

RIZZARDI MA et al. 2004. Manejo e controle de plantas daninhas em milho e sorgo. In: VARGAS L. (Ed.). Manual de Manejo e Controle de Plantas Daninhas. Bento Gonçalves: Embrapa Uva e Vinho. p.571-594.

RODRIGUES ACP et al. 2010. Períodos de interferência de plantas daninhas na cultura do sorgo. Planta Daninha 28 : 23-31.

SILVA AA et al. 2007. Biologia de plantas daninhas. In: SILVA AA \& SILVA FJ (Eds). Tópicos em manejo de plantas daninhas. Viçosa: UFV. p.17-62.

SILVA AG et al. 2015. Desempenho agronômico e econômico de híbridos de sorgo granífero na safrinha em MontividiuGO. Revista de Agricultura 90: 17-30.

TOLK JA et al. 2013. Yield component analysis of grain sorghum grown under water stress. Field Crops Research 145: 44-51.

VASCONCELOS MCC et al. 2012. Interferência de plantas daninhas sobre plantas cultivadas. Agropecuária Científica do Semiárido 8: 1-6. 